\title{
THE ANTIOXIDANT AND PHENOLIC PROFILES OF FIVE GREEN VEGETABLES GROWN IN SOUTHERN NIGERIA
}

\author{
Abiola M. Adeosun ${ }^{1,3 凶}$, Osasenaga M. Ighodaro' ${ }^{1}$, Abiola O. Aminu², \\ Aminat I. Ogunlana ${ }^{2}$ \\ ${ }^{1}$ Department of Biochemistry, Lead City University, Ibadan \\ 1 Oba Otudeko Avenue Toll Gate Area, Ibadan, Oyo State, Nigeria \\ 2Department of Chemistry, Lead City University, Ibadan \\ 1 Oba Otudeko Avenue Toll Gate Area, Ibadan, Oyo State, Nigeria \\ ${ }^{3}$ Institute of Public Analyst of Nigeria \\ World Health Organisation Building 443, Herbert Macaulay Way, Yaba, Lagos, Nigeria
}

\begin{abstract}
Background. Regular consumption of vegetables has been associated with reduced risk of chronic diseases. The phenolic and free radical scavenging properties of five green vegetables grown in southern Nigeria were determined.

Methods. The phenolic and antioxidant profile of African spinach, bitter leaf, jute leaf, scent leaf and water leaf harvested in the month of August were assessed using standard protocols.

Results. The total phenolic content (GAE mg/100 g) of the fresh vegetables ranges from $738.70 \pm 7.90 \mathrm{in}$ African spinach to $1464.63 \pm 7.60$ in scent leaf. A higher flavonoid content (QE mg/100 g) was found in water leaf $(512.07 \pm 1.47)$ and jute leaf $(510.13 \pm 2.22)$ compared to the other vegetables examined; scent leaf $(496.51 \pm 1.31)$, African spinach $(457.40 \pm 1.50)$, bitter leaf $(371.89 \pm 0.44)$. Scent leaf possesses the highest $\mathrm{DPPH}$ radical scavenging activity with an $\mathrm{EC}_{50}[\mu \mathrm{g} / \mathrm{mL}]$ of $74.64 \pm 7.73$. The other vegetables show a lower $\mathrm{EC}_{50}[\mu \mathrm{g} / \mathrm{mL}]$; jute leaf $(125.86 \pm 11.34)>$ water leaf $(132.43 \pm 9.43)>$ bitter leaf $(156.02 \pm 5.43)>$ African spinach $(213.44 \pm 9.29)$. The hydroxyl radical scavenging activity $\left(\mathrm{EC}_{50}, \mu \mathrm{g} / \mathrm{mL}\right)$ of the vegetables in order of decreasing activity, was bitter leaf $(50.38 \pm 7.17)>$ water leaf $(103.41 \pm 6.27)>$ African spinach $(110.54$ $\pm 8.15)>$ jute leaf $(144.39 \pm 9.37)>$ scent leaf $(217.51 \pm 6.90)$. The total antioxidant capacity $\left(\mathrm{EC}_{50}, \mu \mathrm{g} / \mathrm{mL}\right)$ of the vegetables increases in the following order; African spinach $(227.39 \pm 7.25)<$ bitter leaf $(169.96$ $\pm 6.86)<$ water leaf $(106.31 \pm 7.66)<$ scent leaf $(65.47 \pm 14.43)<$ jute leaf $(27.52 \pm 4.14)$.

Conclusions. The green vegetables possess appreciable phenolic and antioxidant potentials, which underscore their regular consumption as part of healthy Nigerian diet. Principal component analysis (PCA) buttresses the correlations and variations of the aforementioned potential among vegetable species.
\end{abstract}

Key words: flavonoid, Nigeria, phenolic, vegetable, oxidative stress, south

\section{INTRODUCTION}

Excessive production of reactive oxygen species, a condition known as oxidative stress, has been linked with pathogenesis of chronic and degenerative diseases, such as; atherosclerosis, ageing, diabetes, hypertension, malignant tumours, inflammation, neurodegenerative and immune disorders (Halliwell and Gutteridge, 1984; Harman, 1998).

Antioxidants are substances that delay or prevent

凶adeosun.amuhammad@lcu.edu.ng, phone +2348069499550 
oxidation from radicals, even at low concentration, compared to that of oxidized substrates (Yan and Liu, 2006). Because of the multifaceted mechanisms of combating oxidative species (Yan and Liu, 2006), regular intake of dietary antioxidants is recommended to synergize the action of endogenous antioxidants.

A diet rich in green vegetables has been linked to reduced incidence of chronic diseases due to their high content of antioxidant compounds ( $\mathrm{Lu}$ and Foo, 2000). Green leafy vegetables are relatively affordable, are present in traditional Nigerian cooking and are readily available, as they grow as weeds around households, gardens and farms in Nigeria. Green leafy vegetables indigenous to Africa have been reported to have health-promoting properties (Opabode and Adebooye, 2005). They are sources of dietary fibre, proteins, minerals, vitamins and essential amino acids, and are low in calories (Muhammad and Shinkafi, 2014). They have been documented to provide $80 \%$ of vitamin A in diets (Kwenin et al., 2011). An increased intake of vegetables has been reported to be an effective strategy to reduce calorie intake and improve health-related quality of life (Blatt et al., 2011).

Scent leaf (Ocimum gratissimum) belongs to the plant family of Labiatae. It is a vegetable widely used in cooking and medicine (Ighodaro et al., 2010). Scent leaves are usually consumed as cooked soup. Bitter leaf (Vernonia amygdalina), from the plant family of Asteraceae, is widely found in markets and planted in home gardens. The leaves are bitter and the bitterness is reduced after boiling. African spinach (Amaranthus hybridus) is a perennial vegetable with an edible stem and leaves. There are pink, deep red and green varieties. The green varieties of the vegetable are grown in Nigerian farms, while other colour varieties are planted for decoration in North America. Water leaf (Talinum triangulare), from the family Portulacaeae, is scientifically classified as a weed. The vegetable grows quickly and has a short life cycle, and is easily propagated by seeds. Talinum triangulare have appreciable mineral and amino acid contents. Jute leaf (Corchorus olitorius) is part of the Malvaceae family and is the primary source of jute fibre. Corchorus species are a good source of nutrients and antioxidant vitamins.

The search for new plant sources of antioxidants has intensified immensely in recent years. In Nigeria, especially in the southern part of the country, the native home of Yoruba and Igbo ethnic groups, these vegetables grow as weeds, can be procured at cheaper price in the markets, and are consumed as part staple diet. In this study, we assessed and compared the antioxidant properties and phenolic contents of African spinach, bitter leaf, jute leaf, scent leaf and water leaf.

\section{MATERIAL AND METHODS}

\section{Chemicals}

Gallic acid, Quercertin, Ammonium phosphomolybdate, Folin reagent, and DPPH were obtained from Sigma Aldrich, USA. Ascorbic acid, Sodium carbonate, and Aluminium Chloride were from BDH, India. Other chemicals and reagents were of analytical grade.

\section{Plant collection}

Fresh vegetables; African spinach (Amaranthus hybri$d u s$ ), jute leaves (Corchorus olitorius), scent leaves (Ocimum gratissimum), water leaves (Talinum triangulare), and bitter leaves (Vernonia amygdalina) were harvested in the month of August from a garden in Ibadan, Oyo State, Nigeria. The leaves were botanically authenticated in Federal College of Forestry, Ibadan, Oyo State, Nigeria by Mr. Ogele E. O.

\section{Sample extract preparation}

The leaves were washed, air dried within three hours, and blended freshly with Nakkai MX320. The blended fresh leaves ( 0.5 grams) were extracted by soaking in $100 \mathrm{~mL}$ of $80 \%$ Methanol for 48 hours. The solutions were centrifuged at $5000 \mathrm{rpm}$ for 15 minutes and the supernatants were stored at $4{ }^{\circ} \mathrm{C}$ prior to in vitro antioxidant assays.

\section{Determination of total phenolic content}

The total phenolic content (TPC) was determined using the spectrophotometric method (Singleton et al., 1999) with the use of Folin-Ciocalteu's phenol reagent at $750 \mathrm{~nm}$. Total phenolic content was determined using gallic acid as standard. The TPC was expressed as gallic acid equivalents (GAE) $[\mathrm{mg} / 100 \mathrm{~g}$ of fresh sample].

\section{Estimation of total flavonoid content}

The amount of total flavonoid content (TFC) was determined using the aluminium chloride spectrophoto- 
Adeosun, A. M., Ighodaro, O. M., Aminu, A. O., Ogunlana, A. I. (2016). The antioxidant and phenolic profiles of five green vegetables grown in Southern Nigeria. Acta Sci. Pol. Technol. Aliment., 15(4), 391-397. DOI: 10.17306/J.AFS.2016.4.37

metric method at $415 \mathrm{~nm}$ (Chang et al., 2002). The flavonoid content was expressed in terms of quercetin equivalent $[\mathrm{mg} / 100 \mathrm{~g}$ of fresh sample].

\section{Anthocyanin contents}

The anthocyanin content (ACC) was evaluated using the $\mathrm{pH}$ differential method (Lim et al., 2012). The results were calculated as cyanidin-3-glucoside equivalents [CGE mg/100 g] of sample fresh weight (FW).

\section{Phosphomolybdate assay (total antioxidant capacity)}

The total antioxidant capacity was determined using the phosphomolybdate method, using ascorbic acid as a standard at $765 \mathrm{~nm}$. (Umamaheswari and Chatterjee, 2008). Then, the $\mathrm{EC}_{50}$ of antioxidant capacity was extrapolated from an activity [\%] vs. concentration graph.

\section{DPPH (2,2'-diphenyl-1-picrylhydrazyl) radical scavenging profile}

DPPH radical scavenging assay was performed using the spectrophotometric method at $517 \mathrm{~nm}$ as described by Brand-Williams et al. (1995). The positive control used was ascorbic acid at $50-500 \mu \mathrm{g} / \mathrm{mL}$. The $\mathrm{EC}_{50}$ of DPPH scavenging activity was extrapolated from an activity [\%] vs. concentration graph.

\section{Hydroxyl radical scavenging activity}

Hydroxyl radical scavenging activities of the samples were determined using the spectrophotometric method at $510 \mathrm{~nm}$ (Smirnoff and Cumbes, 1989). Ascorbic acid was used as a positive control. The $\mathrm{EC}_{50}$ of hydroxyl radical scavenging activity was extrapolated from an activity [\%] vs. concentration graph

\section{Statistical analysis}

All experiments were performed in triplicate. Statistical analyses and graphs were plotted using Graphpad prism 6.04 (GraphPad Software Inc) and SPSS 22.0 (IBM corporation). Significant differences between samples were analysed using One-way ANOVA at $p<0.05$. Phytochemical and antioxidant parameters obtained were subjected to principal component analysis (PCA) to explore the relationship between different variables and samples. Eigen value (Loadings) $>|0.6|$ indicates a significant correlation between the original variables and extracted components. One-way ANOVA and PCA were carried out using SPSS 22.0.

\section{RESULTS AND DISCUSSION}

Table 1 presents the total phenolic (TPC), total flavonoid (TFC) and total anthocyanin (ACC) content of the vegetables. Scent leaf had the highest TPC $(1464.63 \pm 7.90 \mathrm{GAE} \mathrm{mg} / 100 \mathrm{~g})$, exceeding the values in water leaf, jute leaf, bitter leaf, and African spinach by $5.38 \%, 24.37 \%, 41.60 \%$ and $49.56 \%$ respectively. Phenolic compounds are considered secondary metabolites and these phytochemical compounds, derived from phenylalanine and tyrosine, occur ubiquitously in plants. The phenolic content of jute leaf (C. olitorius) observed in this study corroborates with those

Table 1. Phenolic, flavonoids, and anthocyanin content of vegetables

\begin{tabular}{lccc}
\hline \multicolumn{1}{c}{ Samples } & TPC, GAE mg/100 g & TFC, QE mg/100 g & ACC, CGE mg/100 g \\
\hline African spinach (Amaranthus hybridus) & $738.70 \pm 7.90^{*}$ & $457.40 \pm 1.50^{*}$ & $217.09 \pm 3.91^{*}$ \\
Jute leaf (Corchorus olitorius) & $1107.68 \pm 4.90^{*}$ & $510.13 \pm 2.22^{*}$ & $116.89 \pm 4.11^{*}$ \\
Scent leaf (Ocimum gratissinum) & $1464.63 \pm 7.90^{*}$ & $496.51 \pm 1.31^{*}$ & $100.96 \pm 6.28^{*}$ \\
Water leaf (Talinum triangulare) & $1385.88 \pm 33.65^{*}$ & $512.07 \pm 1.47^{*}$ & $166.98 \pm 3.20^{*}$ \\
Bitter leaf (Vernonia amygdalina) & $855.33 \pm 21.29^{*}$ & $371.89 \pm 0.44^{*}$ & $103.53 \pm 5.12^{*}$ \\
\hline
\end{tabular}

Values were presented as mean $\pm \mathrm{SD}(n=3)$.

${ }^{*}$ Differences are significant when compared with One-way ANOVA at $p<0.05$.

$\mathrm{GAE}$ - gallic acid equivalent. QE - quercertin equivalent. CGE - cyanidin-3-glucoside equivalent.

TPC - total phenolic content. TFC - total flavonoid content. ACC - anthocyanin content. 
Adeosun, A. M., Ighodaro, O. M., Aminu, A. O., Ogunlana, A. I. (2016). The antioxidant and phenolic profiles of five green vegetables grown in Southern Nigeria. Acta Sci. Pol. Technol. Aliment., 15(4), 391-397. DOI: 10.17306/J.AFS.2016.4.37

Table 2. The $\mathrm{EC}_{50}[\mu \mathrm{g} / \mathrm{mL}$ fresh weight $]$ of total antioxidant capacity (TAC), 2,2'-diphenyl-1-picrylhydrazyl $(\mathrm{DPPH})$ and hydroxyl $(\mathrm{OH})$ radical scavenging activity of the vegetable extracts

\begin{tabular}{lccc}
\hline \multicolumn{1}{c}{ Samples } & DPPH & OH & TAC \\
\hline L-ascorbic acids & $89.03 \pm 14.82$ & $178.23 \pm 4.13$ & $188.29 \pm 7.48$ \\
African spinach & $213.44 \pm 9.29^{\mathrm{a}}$ & $110.54 \pm 8.15^{\mathrm{a}}$ & $227.39 \pm 7.25^{\mathrm{a}}$ \\
Jute leaf & $125.86 \pm 11.34^{\mathrm{a}}$ & $144.39 \pm 9.37^{\mathrm{a}}$ & $27.52 \pm 4.14^{\mathrm{a}}$ \\
Scent leaf & $74.64 \pm 7.73^{\mathrm{a}}$ & $217.52 \pm 6.90^{\mathrm{a}}$ & $65.47 \pm 14.43^{\mathrm{a}}$ \\
Water leaf & $132.43 \pm 9.43^{\mathrm{a}}$ & $103.41 \pm 6.27^{\mathrm{a}}$ & $106.31 \pm 7.66^{\mathrm{a}}$ \\
Bitter leaf & $156.02 \pm 5.43^{\mathrm{a}}$ & $50.38 \pm 7.17^{\mathrm{a}}$ & $169.96 \pm 6.86^{\mathrm{a}}$ \\
\hline
\end{tabular}

Values were presented as mean $\pm \mathrm{SD}(n=3)$.

aDifferences are significant when compared using One-way ANOVA $(p<0.05)$.

$\mathrm{DPPH}-\mathrm{EC}_{50}$ of DPPH radical scavenging activity. $\mathrm{OH}-\mathrm{EC}_{50}$ of hydroxyl radical scavenging activity.

$\mathrm{TAC}-\mathrm{EC}_{50}$ of total antioxidant capacity.

obtained in other Corchorus species in previous studies (Ademiluyi et al., 2015; Katerere et al., 2012).

Flavonoids and their derivatives are a group of polyphenols that are present naturally in food and medicinal plants, and are known for their antioxidant or free radical scavenging properties (Kar, 2007; Nunes et al., 2012). Over four thousand flavonoids are known to exist and some of them are pigments in higher plants. Quercetin, kaempferol and quercitrin are common flavonoids present in nearly $70 \%$ of plants (Kar, 2007). The total flavonoid content (TFC) content was found to be high in water leaf, then followed respectively by; jute leaf $>$ scent leaf $>$ African spinach $>$ bitter leaf. Total anthocyanin content (ACC) decreased in the following order; African spinach $>$ water leaf $>$ jute leaf $>$ bitter leaf $>$ scent leaf.

Scent leaf has high DPPH radical scavenging activity $(74.64 \pm 7.73 \mu \mathrm{g} / \mathrm{mL})$ compared to L-ascorbic acid $(89.03 \pm 14.82 \mu \mathrm{g} / \mathrm{mL})$, while the others, in decreasing order of activity, are; jute leaf $>$ water leaf $>$ bitter leaf $>$ African spinach (Table 2, Fig. 1). The DPPH scavenging assays explain the possible ways by which antioxidants could help to reduce biological free radicals. Oil extracted from scent leaf has been reported to have potent antioxidant activity (Chanda et al., 2011). The $\mathrm{EC}_{50}$ of the DPPH scavenging effect of scent leaf (Ocimum gratissinum) is lower, which contrasts to the high DPPH radical scavenging profile obtained in the essential oil of Ocimum canum (Selvi et al., 2015).

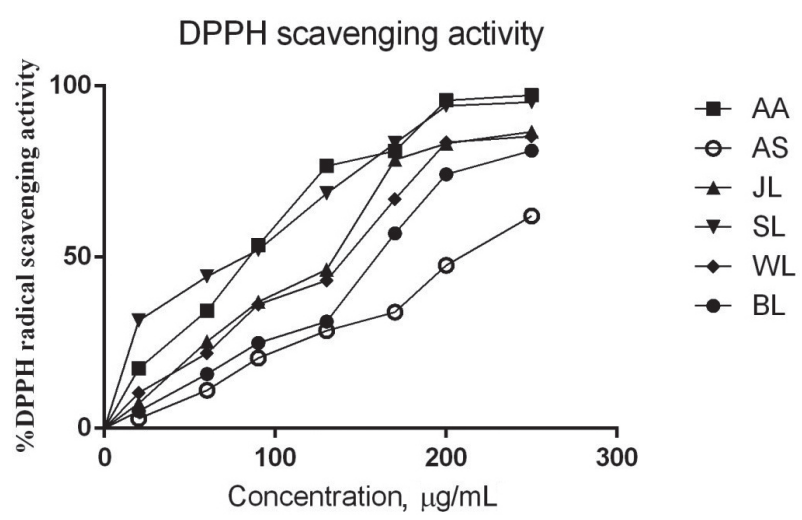

Fig. 1. DPPH scavenging activities of vegetable extracts: AA - ascorbic acid, AS - African spinach, JL - jute leaf, SL - scent leaf, WL - water leaf, BL - bitter leaf

This substantiates claims of some studies that crude plant extracts possesses greater antioxidant properties compared to fractionated extract of the same plant.

Hydroxyl radicals react with polyunsaturated fatty acids in the cell membrane (phospholipids) and consequently causes damage to the cell (Halliwel and Gutteridge, 1981). The hydroxyl radical scavenging activity of bitter leaf, water leaf, African spinach, and jute leaf respectively were good compared to L-ascorbic acid, while scent leaf had the least hydroxyl radical scavenging activity (Table 2, Fig. 2). 
Hydroxyl radical scavenging activity

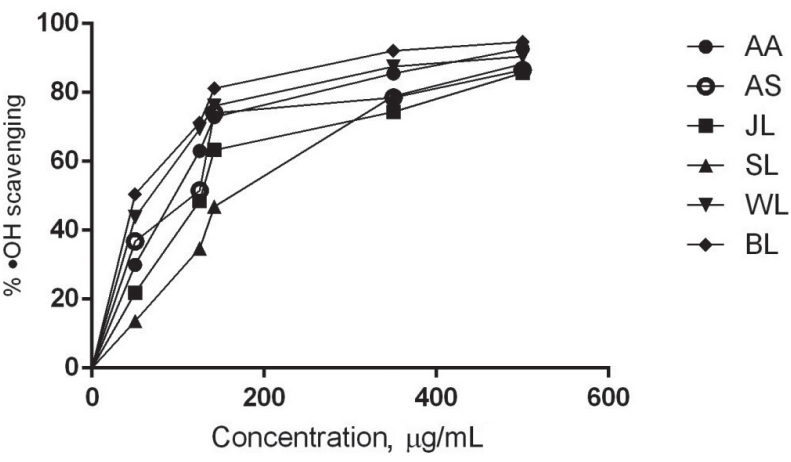

Fig. 2. Hydroxyl radical scavenging activities of vegetable extracts: AA - ascorbic acid, AS - African spinach, JL - jute leaf, $\mathrm{SL}$ - scent leaf, WL - water leaf, BL - bitter leaf

The determination of total antioxidant capacity was based on the reduction of Mo (VI) to Mo (V) by the samples. African spinach has the least total antioxidant capacity $(227.39 \pm 7.25 \mu \mathrm{g} / \mathrm{mL})$, lower than that of L-ascorbic acid $(188.29 \pm 7.48 \mu \mathrm{g} / \mathrm{mL})$. However, the other vegetables assessed in this study have a higher total antioxidant capacity than L-ascorbic acid (Table 2, Fig. 3).

Principal component analysis (PCA) has been proved to provide an in-depth approach to study correlation and variation among species with respect to traits (variables) (Colonna et al., 2016). A two dimensional principal component analysis (PCA) was

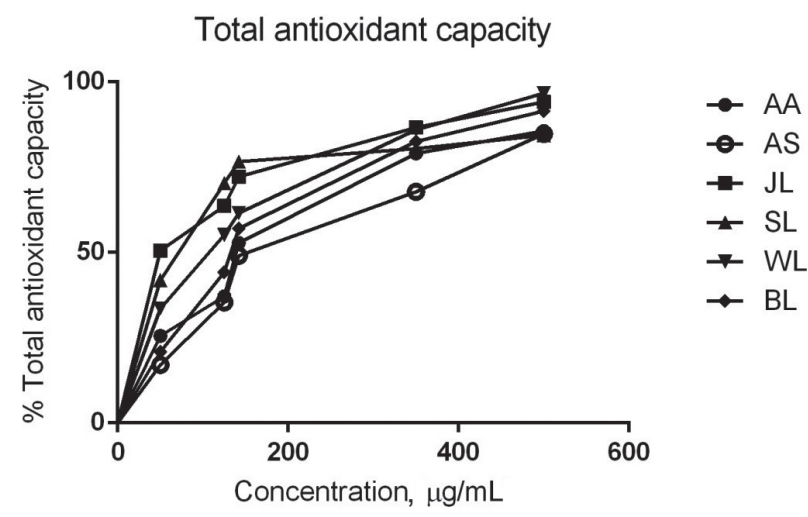

Fig. 3. Total antioxidant capacity of vegetable extracts: AA - ascorbic acid, AS - African spinach, JL - jute leaf, SL scent leaf, WL - water leaf, BL - bitter leaf performed in order to identify and summarise behavioural clusters among phytochemical and antioxidant profiles across the vegetable species. The PC1 and PC2 explained $71.25 \%$ and $27.13 \%$ of the variance respectively. $\mathrm{PC} 1$ was positively and significantly correlated with DPPH, ACC, and TAC, while PC2 was positively and significantly correlated with TFC (Table 3). The loading plot (Fig. 4A) shows a relationship between phytochemicals and the antioxidant profiles of the vegetables. Variables with angle $<90^{\circ}$ between them are strongly correlated, while those with angle $>90^{\circ}$ are weakly correlated or strong in variance. For example, TPC was strongly correlated with TFC and $\mathrm{OH}$. Likewise, ACC was strongly correlated with DPPH and TAC. However, TAC, DPPH and ACC were not correlated with TFC, TPC and $\mathrm{OH}$ (Fig. 4A). The component object score plots (Fig. 4B) discriminate the vegetable species into four quadrants. The positive side of $\mathrm{PC} 1$ in the lower right quadrant included African spinach and bitter leaf, which were characterised by low total antioxidant capacities and

Table 3. Eigen values, relative proportion of total variance and correlation coefficients of phytochemical and antioxidant components with respect to the two principal components

\begin{tabular}{lcc}
\hline \multicolumn{1}{c}{ Principal components } & PC1 & PC2 \\
\hline Eigen values & 4.28 & 1.63 \\
Percentage of variance & 71.25 & 27.13 \\
Cumulative variance & 71.25 & 98.38
\end{tabular}

Eigen vectors

\begin{tabular}{lrr} 
TPC & $\mathbf{- 0 . 9 7 5}$ & 0.202 \\
TFC & -0.142 & $\mathbf{0 . 9 7 7}$ \\
ACC & $\mathbf{0 . 9 1 9}$ & 0.392 \\
DPPH & $\mathbf{0 . 9 9 7}$ & 0.074 \\
OH & $\mathbf{0 . 9 1 3}$ & -0.391 \\
TAC & $\mathbf{0 . 7 9 4}$ & -0.566 \\
\hline
\end{tabular}

Bold characters are markedly significant in the component. $\mathrm{ACC}$ - total anthocyanin content. DPPH - $\mathrm{EC}_{50}$ of DPPH radical scavenging activity. $\mathrm{OH}-\mathrm{EC}_{50}$ of hydroxyl radical scavenging activity. TPC - total phenolic content. TFC - total flavonoid content. TAC $-\mathrm{EC}_{50}$ of total antioxidant capacity. 

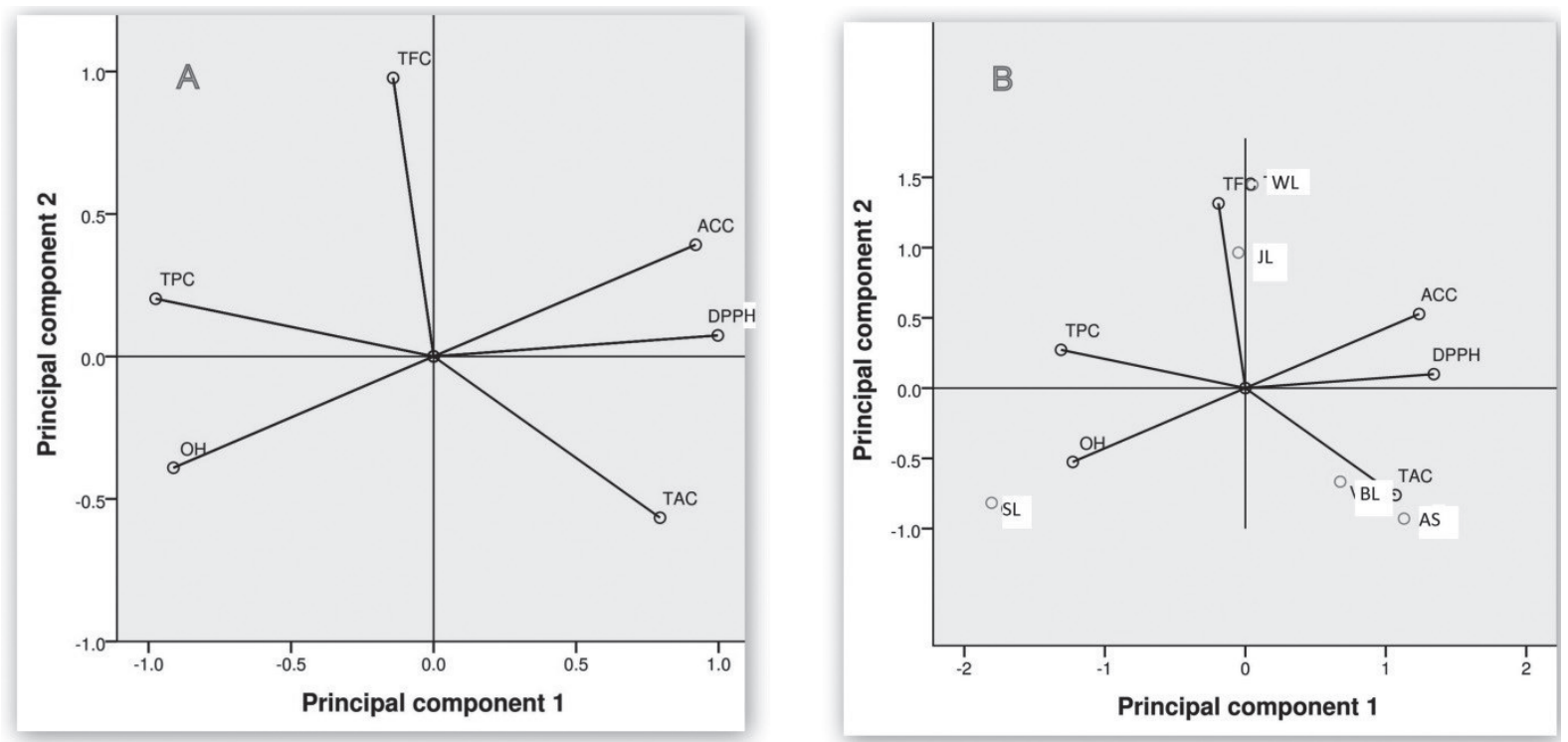

Fig. 4. (A) Loading plot. (B) Component score biplot of the first and second principal component on phytochemical and antioxidant profiles of green vegetables: $\mathrm{ACC}$ - total anthocyanin content, $\mathrm{DPPH}-\mathrm{EC}_{50}$ of DPPH radical scavenging activity, $\mathrm{OH}-\mathrm{EC}_{50}$ of hydroxyl radical scavenging activity, $\mathrm{TPC}$ - total phenolic content, TFC - total flavonoid content, TAC - $\mathrm{EC}_{50}$ of total antioxidant capacity, $\mathrm{AS}$ - African spinach, JL - jute leaf, SL - scent leaf, WL - water leaf, $\mathrm{BL}$ - bitter leaf

low DPPH radical scavenging activities (i.e. they have high $\mathrm{EC}_{50}$ value). On the lower left side of $\mathrm{PC} 1$ is the scent leaf, which is characterised by high phenolic content and low hydroxyl radical scavenging activity. At the midline of the upper quadrants are water leaf and jute leaf, which were characterised by high flavonoid content. Jute leaf and water leaf also have high phenolic content, and possess high DPPH radical scavenging activities, high hydroxyl radical scavenging activities and high total antioxidant capacities. However, scent leaf, with the highest phenolic content among these vegetables, has low hydroxyl radical scavenging activity. This indicates that some phenolic compounds in scent leaf may have lower affinity to scavenge hydroxyl radicals. Compared to the aforementioned vegetables, bitter leaf and African spinach have lower phenolic and flavonoid contents, which relates their lower DPPH scavenging activity and total antioxidant capacities. However, they possess a higher anthocyanin content and higher hydroxyl radical scavenging activities. In this study, the PCA provided an in-depth understanding of correlation and variability among phytochemicals and antioxidant properties of these vegetables. This analysis provided the ability to score vegetable species based on their compositions and potentials.

\section{CONCLUSIONS}

Water leaf and jute leaf possess high flavonoid content. The highest phenolic content was found in scent leaf, but it has a lower flavonoid content compared to those mentioned earlier. African spinach possesses the highest anthocyanin content. African spinach and bitter leaf have low DPPH radical and phosphomolybdate scavenging effects, which can be attributed to their low phenolic and flavonoid contents compared to the other vegetables. African spinach, bitter leaf, jute leaf and water leaf exhibit good hydroxyl radical scavenging properties. However, scent leaf possesses a low hydroxyl radical scavenging profile, despite a high phenolic content. This shows that some phenolic compounds in this vegetable may have low antioxidant potentials. 


\section{ACKNOWLEDGEMENT}

We also acknowledge the Laboratory Technologists of the Department of Biochemistry; Mrs. J. Hassan, Ekeolu BM, and Mr. A. Fashina for their support.

\section{REFERENCES}

Ademiluyi, A. O., Oboh, G., Aragbaiye, F. P., Oyeleye, S. I., Ogunsuyi, O. B. (2015). Antioxidant properties and in vitro a-amylase and a-glucosidase inhibitory properties of phenolics constituents from different varieties of Corchorus spp. J. Taibah Univ. Med. Sci., 10, 278-287.

Blatt, A. D., Roe, L. S., Rolls, B. J. (2011). Hidden vegetables: an effective strategy to reduce energy intake and increase vegetable intake in adults. Am. J. Clin. Nutr., 93,756-763.

Brand-Williams, W., Cuvelier, M. E., Berset, C. (1995). Use of free radical method to evaluate antioxidant activity. Lebensmitt.-Wiss. u- Technol., 28, 25-30.

Chanda, S., Dave, R., Kaneria, M. (2011). In vitro antioxidant property of some Indian medicinal plants. Res. J. Med. Plant, 5,169-179.

Chang, C., Yang, M., Wen, H., Chern, J. (2002). Estimation of total flavonoid content in propolis by two complementary colorimetric methods. J. Food Drug Anal., $10,178-82$.

Colonna, E., Rouphael, Y., Barbieri, G., De Pascale, S. (2016). Nutritional quality of ten leafy vegetables harvested at two light Intensities. Food Chem., 199, 702-710.

Halliwel, B., Gutteridge, J. M. (1981). Formation of thiobarbituric acid reactive substances from deoxyribose in the presence of iron salts: the role of superoxide and hydroxyl radicals. FEBS Lett., 128, 347-52.

Halliwell, B., Gutteridge, J. M. (1984). Oxygen toxicity, oxygen radicals, transition metals and disease. J. Biochem., 219, 1-14.

Harman, D. (1998). Free radical theory of aging; Current status (pp. 3-7). Amsterdam: Elsevier.

Ighodaro, O., Agunbiade, S., Akintobi, O. (2010). Phytotoxic and antimicrobial activities of flavonoids in Ocimum gratissimum. Eur. J. Appl. Sci., 2, 37-40.

Kar, A. (2007). Pharmacognosy and pharmacobiotechnology (pp. 332-600). New Age Int. Publ.
Katerere, D. R., Graziani, G., Thembo, K. M., Nyazema, N. Z., Ritieni, A. (2012). Antioxidant activity of some African medicinal and dietary leafy African vegetables. African J. Biotechn., 11, 4013-4018.

Kwenin, W. K., Wolli, M., Dzomeku, B. M. (2011). Assessing the nutritional value of some African indigenous green leafy vegetables in Ghana. J. Anim. Plant Sci., 10, 1300-1305.

Lim, S. H., Sohn, S. H., Kim, D. H., Kim, J. K., Lee, J. Y., Kim, Y. M., Ha, S. H. (2012). Use of an anthocyanin production phenotype as a visible selection marker system in transgenic tobacco plant. Plant Biotechn. Rep., 6(3), 203-211.

Lu, Y., Foo, Y. L. (2000). Antioxidant and radical scavenging activities of polyphenols from apple pomace. Food Chem., 68, 81-85.

Muhammad, S., Shinkafi, M. A. (2014). Ethno-botanical survey of some medicinal important leafy vegetables in North Western Nigeria. J. Med. Plants Res., 8, 6-8.

Nunes, P. X., Silva, S. F., Guedes, R. J., Almeida, S. (2012). Biological oxidations and antioxidant activity of natural products. In R. Venketeshwer (Ed.), Phytochemicals as nutraceuticals - Global approaches to their role in nutrition and health. InTech [open access publisher]. DOI: $10.5772 / 26956$

Opabode, J., Adebooye, O. (2005). Application of biotechnology for the improvement of Nigerian indigenous leaf vegetables. Afr. J. Biotechnol., 4, 138-142.

Selvi, M. T., Thirugnanasampandan, R., Sundarammal, S. (2015). Antioxidant and cytotoxic activities of essential oil of Ocimum canum Sims from India. J. Saudi Chem. Soc., 19, 97-100.

Singleton, V. L., Orthofer, R., Lamuela-Raventos, R. M. (1999). Analysis of total phenols and other oxidation substrates and antioxidants by means of Folin-Ciocalteu reagents. Method Enzymol., 299, 152-178.

Smirnoff, N., Cumbes, Q. J. (1989). Hydroxyl radical scavenging activity of compatible solutes. Phytochemistry, 28, 1057-1060.

Umamaheswari, M., Chatterjee, T. K. (2008). In vitro antioxidant activities of the fractions of Coccinnia grandis L. leaf extract. Afr. J. Trad. Compl. Altern. Med., 5, 61-73.

Yan, H., Liu, T. (2006). Vitamin A's action of anti-oxidation and promoting oxidation. China Pharmac., 15, 3-5. 